\title{
A pink year
}

We are now celebrating our first year as Editors of CSP. From the choice of the cover's color to the photos honoring women, we have learned what it means to be Editors-in-Chief. We three Editors share equal responsibilities. We have managed to create a truly shared vision. We enjoy working together, accepting our different approaches and especially learning from each other through countless meetings, thinking out loud and moving from subject to subject. In the collective Editorials, one writes, another rewrites, and the third comments, until we never know who wrote the final text. We choose themes for each Editorial by focusing on the journal's readers and authors, discussing free access, editorial independence, painstaking production of articles, and the search for a creative science, capable of truly impacting health and health systems. A key question of the Editorial decisions is how CSP can fulfill its role of contributing to scientific development in the field of Public Health.

Little by little we have honed our publishing policy and learned to better identify articles that need to be turned down, before submitting them to our reviewers. We believe that this practice has lightened the workload for associate editors and reviewers, while informing the authors quickly. We feel that everyone gains from this increased efficiency, including the authors themselves, who can redirect their papers' submissions elsewhere without unnecessary delay.

Among the changes in 2013, the Perspectives section opened space for current contextual issues. Renowned authors have approached a wide variety of themes (race, genetics, drug policy, contemporary physicians, conscientious objection, patient safety, and others). By definition, Public Health involves intervention, and it is our job to encourage reflection on questions that pose challenges and generate polemics. After all, this year featured several lively debates. From the issue of food insecurity (vol.29, n.2) to the debate on researchers' scientific output (vol.29, n.9), focused on a problem that affects Brazil's science production as a whole. As in every fruitful debate, we believe that the various arguments influencied the direction of this discussion in our field. The debate (vol.29, n.10) on the $25^{\text {th }}$ anniversary of Brazilian Unified National Health System (SUS) will echo for a long time to come, having arrived in the midst of controversy and even bewilderment over various aspects of the country's health system. The journal also published the Supplement on Health Technology Assessment with an important sample of Brazilian work on a fundamentally theme for the SUS.

When we took over as Editors, we were aware of the huge transformation underway in science journals and have attempted to unravel such change. Even when journals continue in their traditional print format, they maintain creative websites, with a wide variety of contents and new technologies to enhance the presentation of research and increase exchange with readers. A whole world of possibilities is unfolding for science communication and dissemination. We began to take the first steps in this direction, one of the main challenges for 2014.

It was indeed a pink year. In this daily task of producing and rethinking CSP, we have been joined by the associate editors, reviewers, assistant editors, all the CSP staff, friends, and the authors that submitted their manuscripts for publication on our pages. We thank them and wish them all a Happy New Year. Finally, we want to express acknowledgements to the ENSP/Fiocruz for supporting the work of CSP and the principles of editorial independence.

\author{
Marilia Sá Carvalho \\ Claudia Travassos \\ Cláudia Medina Coeli \\ Editors
}

